Madrygal. Revista de Estudios Gallegos

ISSN: 1138-9664

\title{
El continuum oralidad-"literacidad" en entornos biculturales y bilingües: el gallego y el español nuevo mexicano tradicional
}

\author{
Obdulia Castro $^{1}$; Gabriela DeRobles ${ }^{2}$
}

Recibido: 11 de abril de 2016 / Aceptado: 12 de abril de 2018

Resumen. En la Península Ibérica, el gallego, una lengua romance hablada en el noroeste de España que, después de alcanzar un alto desarrollo como lengua escrita en la Edad Media, sobrevivió como lengua fundamentalmente oral durante siglos, se encuentra hoy en busca de una variedad estándar que le ayude a sobrevivir y le defina un espacio propio entre el portugués y el castellano. En los Estados Unidos, el español nuevo mexicano tradicional (ENMT), una variedad del español asociada con Nuevo México y el sur de Colorado y reconocida como la variedad del español más antigua de América, está a punto de desaparecer, o ya ha desaparecido, inmersa entre diferentes variedades lingüísticas y la norma estándar del español y el inglés. Tanto el gallego como el ENMT han pasado a través de su historia por etapas de literacidad y de oralidad. Con el fin de examinar la relación entre la identidad cultural y lingüística en referencia al continuum oralidad-literacidad, este artículo comparte los resultados preliminares de un proyecto de investigación en proceso que incluye una exploración comparativa de las situaciones sociolingüísticas del gallego en España y el español nuevo mexicano tradicional en Estados Unidos.

Palabras clave: Gallego; español nuevo mexicano tradicional; oralidad; literacidad; mantenimiento lingüístico; cambio lingüístico; lenguas en contacto; desarrollo intercultural.

\section{[gal] O continuum da oralidade-"literacidade" en entornos biculturais e bilingues: o galego e o español novo mexicano tradicional}

Resumo. Na Península Ibérica, o galego, unha lingua romance falada no noroeste de España que, tras acadar un alto desenvolvemento como lingua escrita na Idade Media, sobreviviu como lingua fundamentalmente oral durante séculos, encóntrase hoxe na procura dunha variedade estándar que lle axude a sobrevivir e definir o seu propio espazo entre o portugués e o castelán. Nos Estados Unidos, o español novo mexicano tradicional (ENMT), unha variedade do español asociada con Nuevo México e o sur de Colorado e recoñecida como a variedade do español máis antiga de América, está a punto de desaparecer, ou xa ten desaparecido, no medio de diferentes variedades lingüísticas e a norma estándar do español e o inglés. Tanto o galego como o ENMT pasaron na historia por etapas de literacidade e oralidade. Co fin de avaliar a relación entre a identidade cultural e lingüística no que se refire ao continuum oralidade-"literacidade", este artigo comparte os resultados preliminares dun proxecto de investigación en proceso que inclúe unha exploración comparativa da situación sociolingüística do galego en España e do español novo mexicano tradicional nos Estados Unidos.

Palabras chave: Galego; español novo mexicano tradicional; oralidade: literacidade; mantemento lingüístico; cambio lingüístico; linguas en contacto; desenvolvemento intercultural.

\section{[en] The Orality-Literacy Continuum in Bicultural and Bilingual Environments: Galician and Traditional New Mexican Spanish}

Abstract. In the Iberian Peninsula, Galician, a language spoken in Northwest Spain that, after reaching a high point of development as a written language in the Middle Ages, survived as a mostly oral language for centuries, finds itself today looking for a standard variety that would help it survive and define its own space between Portuguese and Castilian Spanish. In the United States, Traditional New Mexican Spanish (TNMS), a variety of Spanish associated with

1 Regis University (Denver Colorado).

Correo-e: ocastro@regis.edu

2 Georgetown University (Washington, D.C.).

Correo-e: gd443@georgetown.edu 
New Mexico and Southern Colorado and recognized as the oldest known variety of Spanish in the Americas, is about to disappear, or has already disappeared, immersed within different linguistic varieties and standard forms of Spanish and English. Both Galician and TNMS have historically gone through stages of literacy and orality. With the goal to examine the relationship between cultural and linguistic identity as it relates to the orality-literacy continuum, this article shares preliminary results of a research project in progress that includes a comparative look at the socio-linguistic situations of Galician in Spain and Traditional New Mexican Spanish in the US.

Keywords: Galician; Traditional New Mexican Spanish; Orality; Literacy; Language Maintenance; Language Change; Languages in Contact; Intercultural Development.

Sumario. 1. Introducción. 2. Descripción del proyecto. 2.1. Contexto y significado. 3. Metodología. 3.1. Identificación. 3.2. Herramientas usadas. 4. Información demográfica de los participantes. 4.1. Edad. 4.2. Sexo. 4.3. Lugar de origen. 4.4. Nivel educativo. 4.5. Ocupación. 5. Resultados y análisis. 5.1. Identidad. 5.2. Primera lengua. 5.3. Lengua de mayor uso. 5.4. Lengua hablada en la escuela. 5.5. Lengua hablada en el trabajo. 5.6. Lengua de la escritura. 5.7. Lengua de la lectura. 5.8. Lengua y cultura. 6. Conclusiones y dirección de la investigación futura. 7. Referencias bibliográficas.

Cómo citar: Castro, O. y G. DeRobles (2018): "El continuum oralidad-"literacidad" en entornos biculturales y bilingües: el gallego y el español nuevo mexicano tradicional", en Madrygal. Revista de Estudios Gallegos 21, pp. 33-50.

\section{Introducción}

El desarrollo de la "literacidad", entendida no solo como la habilidad de leer y escribir sino como la habilidad de interactuar con la lectura y la escritura en una forma comprensiva e interactiva, ha sido tradicionalmente asociado con el mantenimiento de lenguas. Sin embargo, los efectos de la introducción o reintroducción de la literacidad en entornos mayormente orales dentro de contextos de lenguas minoritarias o minorizadas y/o variedades lingüísticas extraordinariamente diferentes, no han sido suficientemente estudiados. Las situaciones lingüísticas del llamado español nuevo mexicano tradicional, una variedad de español asociada con áreas de Nuevo México y el sur de Colorado en los Estados Unidos, y el gallego, una lengua hablada en el noroeste de España, muestran evidencia de la necesidad de examinar el continuum oralidad-literacidad con mayor detalle.

Walter Ong (1982) introdujo los conceptos de oralidad y literacidad, relacionando la oralidad con sociedades donde no se ha desarrollado la escritura y la literacidad con sociedades donde la escritura está bien establecida. Desde la introducción de estos conceptos se han dado pasos hacia su definición no como fenómenos separados sino como parte de un continuum. Tannen $(1982,1988)$ introdujo el continuum oralidad-literacidad considerando los dos elementos no como una dicotomía, sino como partes entrelazadas del discurso: hay elementos de literacidad en contextos orales y elementos de oralidad en contextos escritos. Aunque tomamos la idea del continuum oralidad-literacidad de Tannen, nosotros ampliamos la idea para incluir la interacción de la oralidad y la literacidad no solo dentro del discurso sino también en la progresión de culturas orales a culturas escritas incluyendo contextos donde encontramos lenguas mayormente orales en contacto con lenguas escritas.

Desde la perspectiva anterior, se podría intentar definir el continuum oralidad-literacidad como un proceso unidireccional, siendo la oralidad el inicio y la literacidad la culminación. En este trabajo, conscientes de la necesidad de representar la posibilidad de movimiento dentro del continuum oralidad-literacidad, lo consideraremos como un continuum no-unidireccional; es decir, un grupo lingüístico puede encontrarse más cerca de la oralidad o más cerca de la literacidad y su posición en el continuum puede variar dependiendo de múltiples circunstancias. En otras palabras, un grupo que ha desarrollado un grado de literacidad en una lengua nativa puede verlo reducido o incluso perderlo debido a diferentes circunstancias: la

3 Aunque la Real Academia de la Lengua Española todavía no incluye el término "literacidad" en su diccionario, hemos escogido este neologismo para hacer referencia al fenómeno de integración de la cultura oral y escrita. El término "literacidad" no se refiere solamente a la capacidad de descifrar y reproducir un código, implicada en la definición relacionada con los términos "lectoescritura" o "alfabetización", sino que también incluye la lectura y la escritura como partes imprescindibles de un proceso lingüístico, sociológico, político, cultural, etc., con claras implicaciones ideológicas. También hemos querido eliminar los elementos negativos asociados a palabras como "analfabetismo/ analfabetos". En todo caso, no somos los primeros en usar este concepto (véanse, entre otros, Ames 2002, Zavala 2002 y 2005, Marí 2005). 
falta o pérdida de acceso a un sistema educativo, la falta de acceso a textos escritos en la lengua nativa, la imposición o presencia de otra lengua como registro escrito, etc.

La historia del gallego es un buen ejemplo de las circunstancias mencionadas. Fue una lengua escrita desde el siglo XII al XV, compitiendo con el latín y el castellano, pero al ser desplazada definitivamente por esta última, desaparece prácticamente del mundo de la escritura y no recupera un sistema estandarizado hasta 1983. El español nuevo mexicano tradicional también tuvo originalmente acceso a un registro escrito: el español estándar del momento, pero esta presencia se redujo por el aislamiento y la falta de recursos. Igual que el gallego en la Península Ibérica perdió la literacidad ante la imposición del castellano como lengua escrita, el español nuevo mexicano tradicional en los Estados Unidos quedó sumergido en la oralidad por el aislamiento y el establecimiento del inglés como lengua escrita.

Con el objetivo de contribuir a un mayor entendimiento de la actual realidad sociolingüística del ENMT ${ }^{4}$ en Nuevo México y el sur de Colorado y el gallego en Galicia, examinaremos los efectos del continuum oralidad-literacidad en el mantenimiento y/o cambio lingüístico. Este trabajo comparte los resultados de un proyecto de investigación en el área del ENMT ${ }^{5}$ y en Galicia (Castro 2015) donde usando una encuesta sociolingüística creada por la investigadora principal y el Inventario de Desarrollo Intercultural (IDI) (Hammer y Bennett 1998, 2002) se recopila información autoevaluada sobre identidad y competencia intercultural y lingüística ${ }^{6}$.

\section{Descripción del proyecto}

\subsection{Contexto y significado}

El gallego y el ENMT, dos situaciones y constructos lingüísticos aparentemente diferentes y únicos, comparten aspectos históricos, políticos y sociales. Históricamente, ambas situaciones lingüísticas han oscilado entre períodos de literacidad y períodos donde la oralidad era la norma. La literacidad, cuando está presente, da lugar a una serie de disociaciones entre los registros orales y escritos incluyendo ejemplos de diglosia dialectal y bilingüe ${ }^{7}$. Tanto el gallego como el ENMT comparten su espacio lingüístico con otras lenguas o variedades lingüísticas. El gallego, situado entre el portugués y el español castellano, tiene variedades estándares y no estándares propias y coexiste con diversas variedades del castellano. El ENMT se encuentra a su vez entre distintas variedades del español y el inglés.

La historia del ENMT empieza en 1598 cuando bajo la dirección de Juan de Oñate, colonos procedentes de distintas regiones de España y la entonces denominada como "la Nueva España" (lo que hoy llamamos México), se asentaron en un área a la que dieron el nombre de "la Nueva México". Este grupo de colonos, cultural y lingüísticamente diverso, estaba compuesto por españoles de diferentes regiones de la Península Ibérica, criollos, mestizos y grupos indígenas que habían aprendido el español como segunda lengua (Sanz y Villa 2011). Este grupo y otros trajeron el español hablado en la Nueva España (México), a lo que hoy es parte del sur de los Estados Unidos. Pérez de Villagrá en 1610 en su Historia de la Nueva México relató en forma escrita las aventuras de Oñate y sus compañeros que permanecieron demográficamente aislados hasta el levantamiento indígena de 1680 que los hizo replegarse a Ciudad Juárez (Roberts y Roberts 1988). No fue hasta 1693 cuando otro grupo de colonos, dirigido por Diego de Vargas, se unió al grupo original para retomar el territorio previamente abandonado donde se mantuvieron alejados de otros centros de población hispana durante más de trescientos años. Este período de aislamiento dio lugar a la aparición

4 El término "español nuevo mexicano tradicional" (ENMT) se usa aquí para referirnos a la variedad del español hablada en zonas de Nuevo México y el sur de Colorado reconocida como diferente y única tanto por sus hablantes nativos como por hablantes de otras variedades del español.

5 La recopilación de datos del español nuevo mexicano tradicional está todavía en proceso. Los datos del gallego fueron recogidos durante el verano y el otoño del 2011 (Castro 2015).

6 Para una descripción de la encuesta véase $\$ 3$ y también Castro 2015.

7 El término "diglosia" ha sido definido como una situación donde dos diferentes variedades de la misma lengua (diglosia dialectal; Ferguson 1959) o dos lenguas diferentes (diglosia bilingüe; Fishman 1967) son usadas en diferentes condiciones dentro de una comunidad lingüística. Una variedad y/o lengua es usualmente identificada como la de bajo prestigio y la otra como la de alto prestigio. 
de una nueva variedad de español propia de esta región (Esquibel y Colligan 1999).

La diversa composición demográfica y dialectal de los primeros nuevomexicanos junto con las características sociohistóricas de la región de Nuevo México crearon las condiciones ideales para la formación de un nuevo dialecto claramente diferente de otras variedades hispanas (Sanz-Sanchez 2013). John Lipski (2008) se refiere a la ausencia de documentación de la fundación de escuelas públicas hasta bastante después de la independencia mexicana, manteniéndose esta región atrasada con respecto al resto del sistema de los Estados Unidos incluso después de la anexión de los territorios de lo que había sido la Nueva México a los Estados Unidos. Según Lipski (2008), el aislamiento de esta comunidad junto con la disminución de la literacidad, la alejó de la memoria colectiva facilitada por la lengua literaria, incluida la poesía, la narrativa y los textos "formulaicos" de la religión, la burocracia y los documentos militares. No obstante, el grupo no estuvo completamente separado de un sistema de literacidad. Steele (2005) menciona al hermano Antonio Margil de Jesús como el iniciador de la evangelización a través de los llamados Alabados: himnos religiosos escritos para ser cantados oralmente con el objeto de mantener la tradición religiosa. La falta de textos escritos y la carencia de educación escolar dejaron a esta comunidad al margen de la literacidad, pero los Alabados, textos escritos disfrazados de oralidad, trajeron el mundo religioso escrito a este grupo aparentemente abandonado convirtiendo lo escrito en oral. Aunque la producción de estos textos está desapareciendo, los Alabados siguen reapareciendo en Nuevo México y el sur de Colorado constituyendo un buen ejemplo de la interacción entre oralidad y literacidad en el español tradicional de esta zona. Steele (2005), después de hacer un estudio comparativo de textos de Alabados, encontró en ellos un número muy pequeño de expresiones "formulaicas" características de textos producidos y difundidos dentro de la oralidad. Por lo tanto, Steele (2005) concluye que no fueron producto de un poeta oral individual sino el fruto de documentos originalmente creados de forma escrita por escritores literatos que tuvieron el cuidado de incluir elementos orales para acercarse a la tradición oral.

Por su parte, el gallego, originario de lo que se ha dado en llamar galaico o gallegoportugués y una de las lenguas romances de la Península
Ibérica, ha sido una lengua oral desde el siglo IX y una lengua escrita desde alrededor de finales del siglo XII (Souto Cabo 2012). El gallegoportugués fue la lengua de la lírica y de la prosa en el espacio peninsular occidental desde el siglo XII al XV: lírica profana, Cantigas de Santa María, Crónica xeral galega, Crónica troiana, Historia troiana, Miragres de Santiago, Crónica de 1404, etc. (Lorenzo 2004, Monteagudo 2007, Mariño Paz 2008, Souto Cabo 2008, 2014; Pena 2013). Durante el siglo XIV, el castellano empieza a reemplazar al gallego como la lengua de literacidad y el gallego es prácticamente desplazado del continuum oralidad-literacidad durante los siglos XVI al XVIII (Lorenzo 2004, Monteagudo 2007). No obstante, continuó siendo usado oralmente y no estuvo completamente ausente del continuum de la escritura (Mariño Paz 2008).

A partir del siglo $\mathrm{XV}$, la situación de contacto entre el gallego y el castellano en Galicia se puede definir como diglósica donde el castellano puede ser identificado como la variedad alta y el gallego como la baja (Valle 2000). El castellano impuso su norma estándar o "norma culta" mientras que el gallego no tuvo un estándar escrito durante mucho tiempo. Sin embargo, hubo producción ocasional de textos en gallego dentro y fuera de Galicia (Mariño Paz 1997, 2007, 2012, 2014; Álvarez y Rodríguez Montederramo 2005, 2004; Álvarez y González Seoane 2016, 2015, Álvarez 2017; véase un balance en Mariño Paz, Sánchez Yáñez y Suárez Vázquez 2012). También encontramos ejemplos de intentos, aunque breves, de estandarización. Uno de ellos es el del Padre Martín Sarmiento, gran defensor de la enseñanza del gallego en el sistema educativo, que en 1746 escribe en gallego el Coloquio de vintecatro galegos rústicos (Mariño Paz 1995, Monteagudo 2002) en un esfuerzo por dejarnos un ejemplo escrito de la lengua hablada: lo oral se hace escrito.

En Nuevo México, el ENMT, al ser usado fundamentalmente en un contexto oral y al ser visto como una variedad dialectal del español, nunca desarrolló un estándar escrito propio, pero los Alabados, cantos de alabanza y lamentación (Steele 2005), fueron el instrumento usado para hacer la literacidad accesible a comunidades principalmente orales. No olvidemos que esto fue hecho imitando la oralidad. Estos Alabados, completamente inmersos en la psiquis de hablantes centrados en la oralidad, ayudaron a mantener su interacción con la literacidad. 
Por otro lado, El Coloquio de vintecatro galegos rústicos (Mariño Paz 1995, Monteagudo 2002) fue un intento de registrar de forma escrita la oralidad presente en Galicia en ese tiempo. Tal vez podamos ver este texto como la mejor expresión de estandarización: tomar la oralidad existente y representarla en forma escrita.

En el suroeste de los Estados Unidos, el tratado de Guadalupe-Hidalgo firmado el 2 de febrero de 1848 , le concedió la ciudadanía estadounidense a todos los mexicanos que permanecieron en el territorio. El tratado también garantizó derechos civiles, políticos y religiosos a los colonos de habla hispana (Acuña 1988). A medida que la población angloparlante empezó a aumentar durante el siglo XIX, las dos culturas entraron en conflicto y las garantías proporcionadas por el tratado no fueron respetadas en muchas ocasiones (Bills 1997). Poco a poco el inglés empezó a convertirse en la lengua del poder. En 1912, Nuevo México se convirtió en estado de la Unión y el español fue reconocido como lengua cooficial. La Constitución de 1912 especificó que todas las leyes debían ser publicadas en español, pero esto no se ha implementado durante mucho tiempo (Government Report 1972). Romero (2011) afirma que Nuevo México ha adoptado el español como lengua cuasi-oficial. Sin embargo, a pesar de ser el estado con el mayor número de población hispana en los Estados Unidos (Pew Research Center 2016), el español no se ha mantenido al mismo nivel que el inglés (Sanz y Villa 2011). Esto es especialmente cierto para el ENMT que, como sostiene Garland Bills (1997), al encontrarse entre dos poderosas fuerzas lingüísticas, el inglés y el español mexicano, ve cómo sus posibilidades de supervivencia son cada vez menores.

En Galicia, con la llegada del Romanticismo en el siglo XVIII se despierta el interés por el estudio del gallego mostrado por autores como el padre Sarmiento, el padre Feijóo y el padre Sobreira, pero hasta el siglo XIX el castellano siguió siendo la lengua utilizada para la literacidad en Galicia mientras que el gallego se mantuvo como lengua de la oralidad (González González 1985, Mariño Paz, Barreiro Fernández y Aneiros Díaz 2008). A principios del siglo XIX vemos un resurgimiento de textos en gallego (Mariño Paz 2012), pero todavía sin la presencia de un esfuerzo de estandarización. No es hasta mediados del siglo XIX donde finalmente empezamos a ver un interés más centrado en la lengua con la producción de diccionarios y gramáticas. Para finales del siglo XIX y principios del siglo XX vemos una gran actividad en la producción de textos literarios en gallego (Monteagudo 1999, Valle 2015). Rosalía de Castro es la máxima representante del período conocido como Rexurdimento con la publicación de sus Cantares Gallegos en 1863. Esto generó un movimiento político y literario hacia la autonomía de Galicia y su lengua, pero dicho reconocimiento fue detenido por el inicio de la Guerra Civil en 1936. Durante la época de Franco, los exiliados, desde fuera, y escritores, editoriales y revistas desde dentro, hicieron todo lo posible para revitalizar el estudio y mantenimiento del gallego, pero hubo que esperar hasta 1979 para que esta lengua fuera introducida en el sistema educativo y hasta 1981 para que fuera reconocida como lengua cooficial junto al castellano. En 1982 la Real Academia Galega y el Instituto da Lingua Galega desarrollaron las normas ortográficas y morfológicas del idioma gallego (NOMIG) que, a su vez, fueron establecidas como las normas básicas del gallego por la Ley de Normalización Lingüística proclamada en 1983 y actualizadas en 2003. Estas normas han sido enseñadas en la escuela y aunque el nivel de literacidad en gallego ha aumentado significativamente, el número de hablantes de gallego ha disminuido, especialmente en las generaciones más jóvenes (Castro 2015, Ramallo 2012).

Por su parte, Bills y Vigil (2008) consideran que el ENMT va a desaparecer, o tal vez ya haya desaparecido debido a la constante inmigración de hablantes de español, especialmente de México ${ }^{8}$. Con respecto a la permanencia del español en los Estados Unidos, estos autores señalan que, a diferencia de los hablantes del nuevo mexicano tradicional que mantuvieron su variedad lingüística por siglos, el español de los inmigrantes hispanos de los siglos XX y XXI solo se mantiene hasta la tercera generación en este país. Es decir, en una familia que ha vivido en los Estados Unidos durante tres generaciones, siendo los abuelos la primera generación en

8 El mantenimiento (o no) del ENMT es uno de los elementos que este proyecto de investigación está tratando de determinar. 
el país, los abuelos mantienen el español, pero sus nietos ya hablan solo inglés. De acuerdo con esto, el español en Nuevo México y el sur de Colorado (y en el resto de los Estados Unidos) parece mantenerse gracias a la llegada continua de inmigrantes de otros países hispanos, especialmente de México (Id.).

\section{Metodología 9}

Con el intento de contribuir al estudio de las posibles conexiones entre el continuum oralidad-literacidad y los conceptos de identidad y desarrollo intercultural en la elección de lengua en Galicia y en Nuevo México y el Sur de Colorado, diseñamos un proyecto de investigación para recopilar información de gallegos y de nuevo mexicanos tradicionales sobre sus percepciones autoevaluadas de su identidad cultural y uso de lenguas ${ }^{10}$.

\subsection{Identificación de participantes ${ }^{11}$}

Galicia. Debido a la centralidad del sistema de educación en la reintroducción de literacidad en gallego, decidimos recoger información de diferentes grupos dentro del sistema educativo: estudiantes y personal docente y administrativo a todos los niveles educativos (primaria, secundaria, universidad), con la intención de observar el estatus del continuum de la identidad gallega y el uso de lenguas con el fin de determinar si eran paralelos y/o intersectaban con la noción del desarrollo intercultural como un continuum. Escogimos estos grupos para (1) examinar la percepción de la efectividad del sistema educativo examinándolo desde dos ángulos: estudiantes e instructores/administradores, y (2) tener un grupo de estudio coherente.
Nuevo México y sur de Colorado. Al decidir duplicar esta metodología para hacer un estudio de la situación del español nuevo mexicano tradicional, la ausencia de la enseñanza sistemática del español estándar o la variedad tradicional de Nuevo México en el sistema educativo nos llevó a no concentrar el estudio en el sistema educativo sino extender la investigación a todos aquellos que cumplieran con los siguientes requisitos de participación:

Identificarse a sí mismo(a) o ser identificado(a) por otros como perteneciente al mundo cultural nuevo mexicano tradicional y/o tener herencia hispánica

Demostrar ser originario de Nuevo México o del sur de Colorado por lo menos durante cinco o seis generaciones. Es decir, al menos uno de sus tras tatarabuelos fue originario de España o de México y nació o llegó a una temprana edad a Nuevo México o el sur de Colorado.

Es necesario mencionar que la recolección de datos del estudio del ENMT está todavía en progreso. Este reporte solo incluye resultados basados en la información recopilada hasta el momento. Los resultados del estudio del ENMT deben ser considerados como preliminares y son incluidos aquí solamente en aquellos casos donde el alto nivel de concordancia entre las respuestas de los participantes tiende a darles un alto grado de confiabilidad. En futuros reportes incluiremos mayor número de detalles.

\subsection{Herramientas usadas ${ }^{12}$}

Se ha utilizado un cuestionario sociolingüístico diseñado por la investigadora principal recopilando información autoevaluada sobre el

Debido a que este proyecto de investigación incluye sujetos humanos, especialmente individuos menores de 18 años, ha tenido que ser revisado y aprobado por el Comité Institucional de Investigación de la institución de la investigadora principal antes de proceder. La metodología de la investigación fue aprobada y todos los protocolos necesarios para la recaudación de información fueron aplicados incluyendo la solicitud de autorización de los padres o guardianes legales de menores de edad y el requisito de que todos los participantes firmaran planillas de consentimiento informado. Todas las encuestas fueron hechas en línea dándoles a los participantes nombres de usuario y contraseñas solamente después de haber recibido sus planillas de consentimiento firmadas.

10 Para mayor detalle véase Castro 2015.

11 De acuerdo al protocolo requerido por las normas de investigación en proyectos usando sujetos humanos seguidos en este trabajo, los participantes tenían la libertad de escoger qué preguntas responder. Para los fines de este trabajo solo se incluye información de 20 participantes del grupo de ENMT y 82 participantes del grupo de Galicia que completaron todas las preguntas.

12 Como parte del proyecto de investigación también se usó el Inventario de Desarrollo Intercultural (IDI): un instrumento psicométrico estandarizado con 50 preguntas basado en el Modelo de Desarrollo de Sensibilidad Intercultural diseñado por Milton Bennet (1993); sin embargo, para los fines de este trabajo solo se reporta información extraída del cuestionario sociolingüístico. 
uso y conocimiento de la lengua y sobre identificación lingüística y cultural ${ }^{13}$. El cuestionario se ofreció en gallego y en castellano en Gali$\mathrm{cia}^{14}$, y en español y en inglés en Nuevo México y el sur de Colorado ${ }^{15}$. Todas las preguntas (excepto dos) fueron diseñadas utilizando una escala de respuesta tipo Likert ${ }^{16}$. Las últimas dos cuestiones son preguntas abiertas donde se pide a los participantes completar las siguientes frases usando toda la información que consideren pertinente y apropiada:

a) Galicia:

- Una persona es considerada gallega si...

- Una persona no es considerada gallega si...

b) Nuevo México y sur de Colorado:

- Una persona es considerada como nuevomexicana tradicional si...

- Una persona no es considerada como nuevomexicana tradicional si...

Las personas interesadas que cumplían los requisitos de participación y que confirmaron por escrito su deseo de participar y de adherirse a las normas de la investigación recibieron las encuestas por vía electrónica.

\section{Información demográfica de los partici- pantes}

Las siguientes figuras incluyen información demográfica sobre los participantes en el proyecto de investigación.

\subsection{Edad}

En la figura 1 podemos ver que mientras la mayoría $(76,47 \%)$ de los participantes del ENMT reportan tener 51 años o más, el grupo de edad más representado en el grupo gallego es el de 14-17 años (41,4\%). Este resultado puede ser parcialmente atribuido al grupo estudiado en cada entorno. En Galicia el estudio estuvo

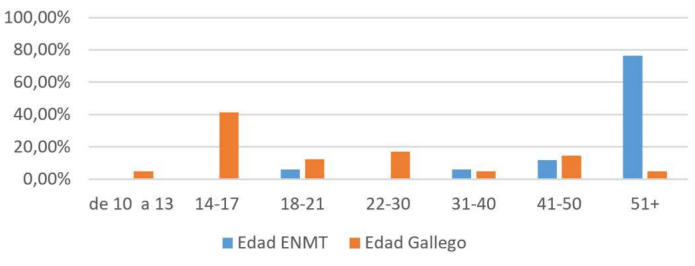

Figura 1. Edad de los participantes

dirigido a instituciones educativas a diferentes niveles, mientras en los Estados Unidos, el estudio fue dirigido a la población general. Es necesario notar que, aunque grupos en edad escolar fueron contactados para participar en el proyecto del ENMT, estos grupos no representan, hasta el momento, un número significativo de los participantes. En entrevistas posteriores a la ejecución de las encuestas, participantes del ENMT entre los 18-21 años han comentado que ellos conocen y usan un número de palabras relacionadas con el ENMT aprendidas en el contexto familiar pero no tienen mucha información sobre el ENMT y consideran que el aprender español, no necesariamente ENMT, es importante en el mundo contemporáneo.

\subsection{Sexo}

Es interesante notar que mientras que en los Estados Unidos la mayoría de los participantes pertenece al sexo masculino (60\%), en Galicia, la mayoría de los participantes pertenece al sexo femenino $(65,06 \%)$.

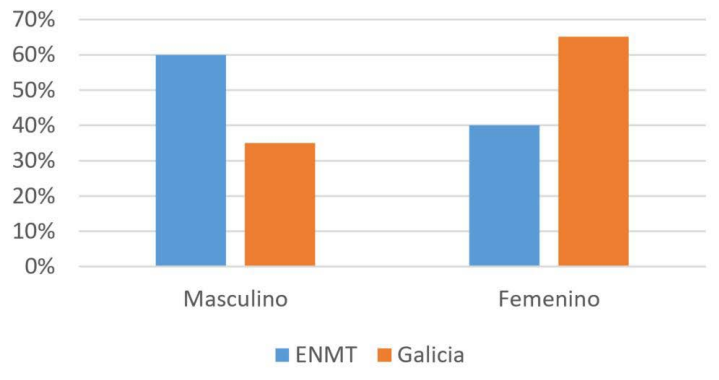

Figura 2. Sexo de los participantes

\footnotetext{
Copia disponible a petición de la persona o personas interesada(s).

Todos los participantes en Galicia escogieron el gallego para completarla.

Todas las respuestas recibidas han sido en inglés.

16 Esta escala psicométrica desarrollada por Rensis Likert en 1932 es la más usada en proyectos de investigación que usan encuestas para recaudar información de sujetos/participantes humanos. Mide actitudes, valores, opiniones, etc. de los sujetos participantes que responden a un cuestionario indicando su grado de acuerdo o desacuerdo con una serie de afirmaciones. Por ejemplo, en nuestro cuestionario sociolingüístico los participantes respondieron, entre otras, a afirmaciones como: "Hablo gallego (ENMT/español/inglés) todos los días" escogiendo entre las siguientes opciones: Totalmente en desacuerdo / En desacuerdo / Más o menos de acuerdo / De acuerdo / Totalmente de acuerdo.
} 


\subsection{Lugar de origen}

Teniendo en mente que la participación en este proyecto es totalmente voluntaria, es interesante notar que tenemos un mayor número de participantes de entornos rurales tanto en Estados Unidos (53\%) como en Galicia (54,88\%).

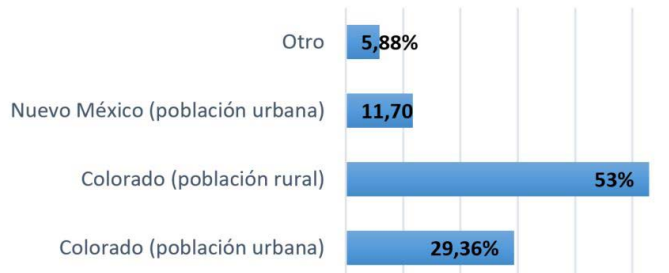

Figura 3. Origen de los participantes (ENMT)

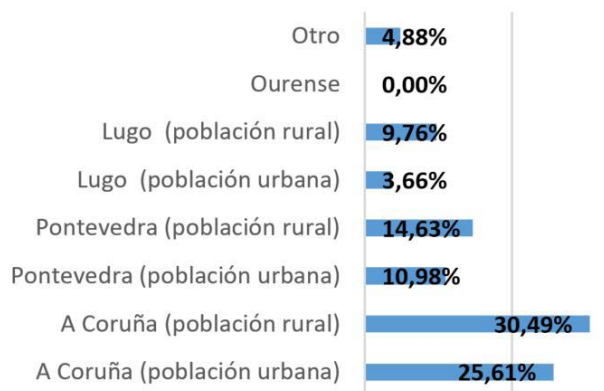

Figura 4. Origen de los participantes (Galicia)

\subsection{Nivel educativo}

No tenemos respuestas de menores de 18 años en el ENMT y esto se refleja en la ausencia en la muestra de participantes que no han finalizado el bachillerato. En Galicia, la mayoría de los participantes es precisamente del grupo de estudiantes: secundaria y universidad.

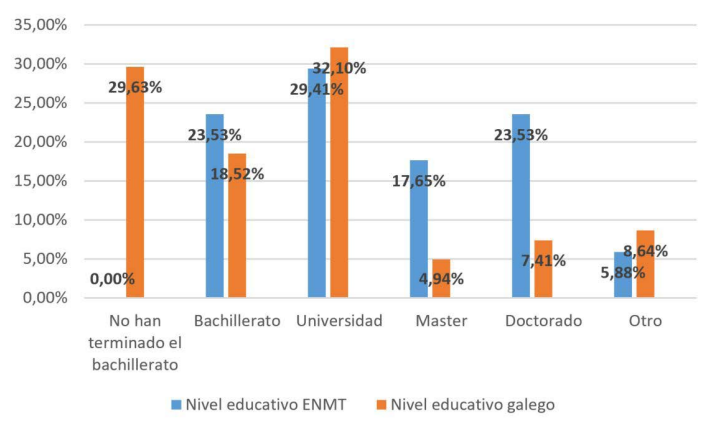

Figura 5. Nivel educativo de los participantes

\subsection{Ocupación}

Como podemos ver en la figura 6, la mayoría de los participantes de Galicia son estudiantes a nivel secundario y universitario. En el ENMT, aunque tenemos igual participación de miembros de otras profesiones (45\%) y de personal docente y administrativo de instituciones educativas $(45 \%)$, los estudiantes son la minoría $(10 \%)$.

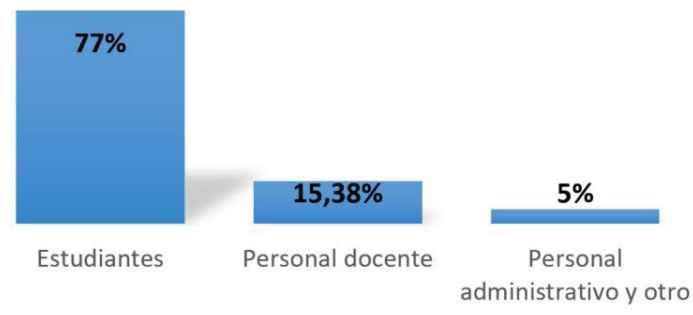

Figura 6. Ocupación de los participantes (Galicia)

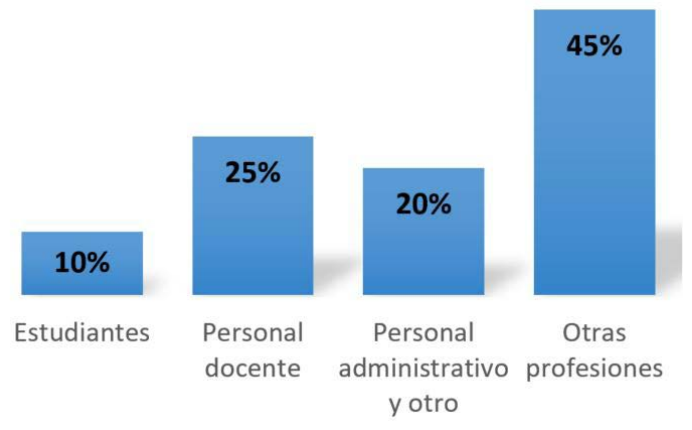

Figura 7. Ocupación de los participantes (ENMT)

\section{Resultados y análisis}

\subsection{Identidad}

Las figuras 8 y 9 representan los resultados de las respuestas a una de las dos preguntas abiertas del cuestionario sociolingüístico. Los participantes podían responder a estas preguntas libremente. Los datos expuestos en estas dos figuras están basados en la totalidad del número de ocasiones en que encontramos el elemento referenciado basado en un análisis de texto. En la encuesta gallega (fig. 8), el orgullo de ser gallego y hablar (oralidad) y/o escribir en gallego son los identificadores más mencionados. En ENMT (fig. 9) las opciones más comunes hasta el momento están relacionadas con tener antepasados y orígenes y/o raíces nuevomexicanas. Es interesante notar que el hecho de hablar o no la variedad lingüística conocida como ENMT no es mencionado como parte de los elementos identificadores. El acento es el único factor lingüístico mencionado por los participantes nuevomexicanos que, al ser un elemento prosódico, puede ser reconocido, aunque se use otra lengua. Esto ocurre 
también en la situación de Galicia donde el acento gallego es también identificado en hablantes monolingües de castellano originarios de Galicia. Es decir, el hablante puede tener acento gallego o nuevomexicano sin necesariamente hablar estas lenguas. Hay que apuntar que el número de incidencias del acento como identificador de "galleguidad" es mínimo (Castro 2017).

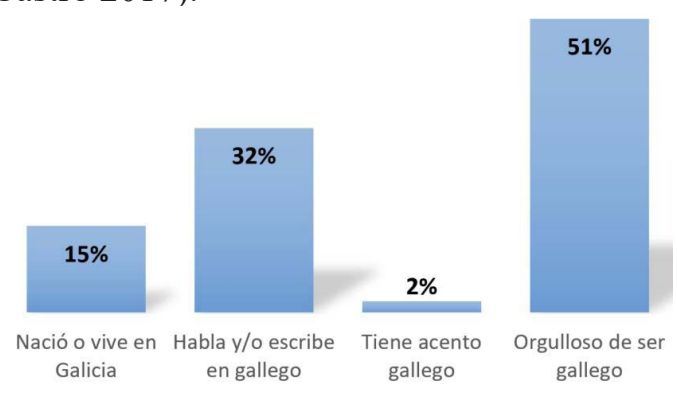

Figura 8. ¿Quién es gallego?

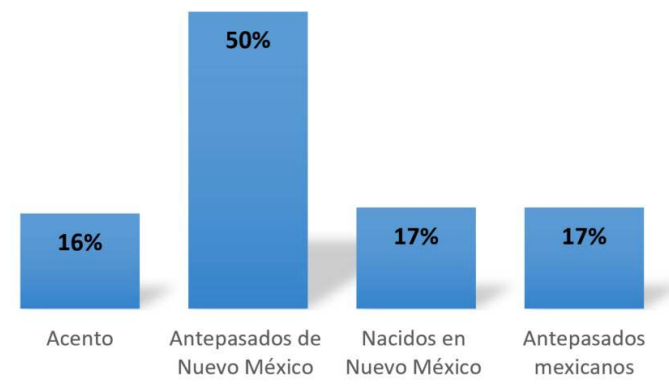

Figura 9. ¿Quién es nuevomexicano tradicional?
Las figuras 10 y 11 representan los elementos referenciados en las respuestas a la segunda pregunta abierta de la encuesta sociolingüística. Los resultados están basados en el número de instancias de los elementos mencionados en las respuestas de los participantes. Una vez más, al tener que especificar lo que determina que alguien no sea identificado como gallego, los participantes (fig. 10) consistentemente consideran el orgullo en la cultura y la lengua como los factores más importantes. Al comparar estos resultados con lo que reportan los participantes en Nuevo México y el sur de Colorado, podemos ver que las respuestas a la pregunta abierta pidiendo la descripción de quién no es considerado como nuevo mexicano tradicional no muestran una preferencia clara, pero en la información compilada (fig. 11) el ser de origen nuevo mexicano o del sur de Colorado y tener ancestros originarios del área son los factores más importantes.

$\mathrm{Si}$ incorporamos las respuestas que requieren un origen mexicano americano, tenemos una mayoría significativa indicando el origen y raíces como los factores más importantes. El no tener acento y no querer mantener el dialecto son también considerados como importantes elementos de identidad, pero, de momento, toman un segundo lugar ante orígenes y raíces.
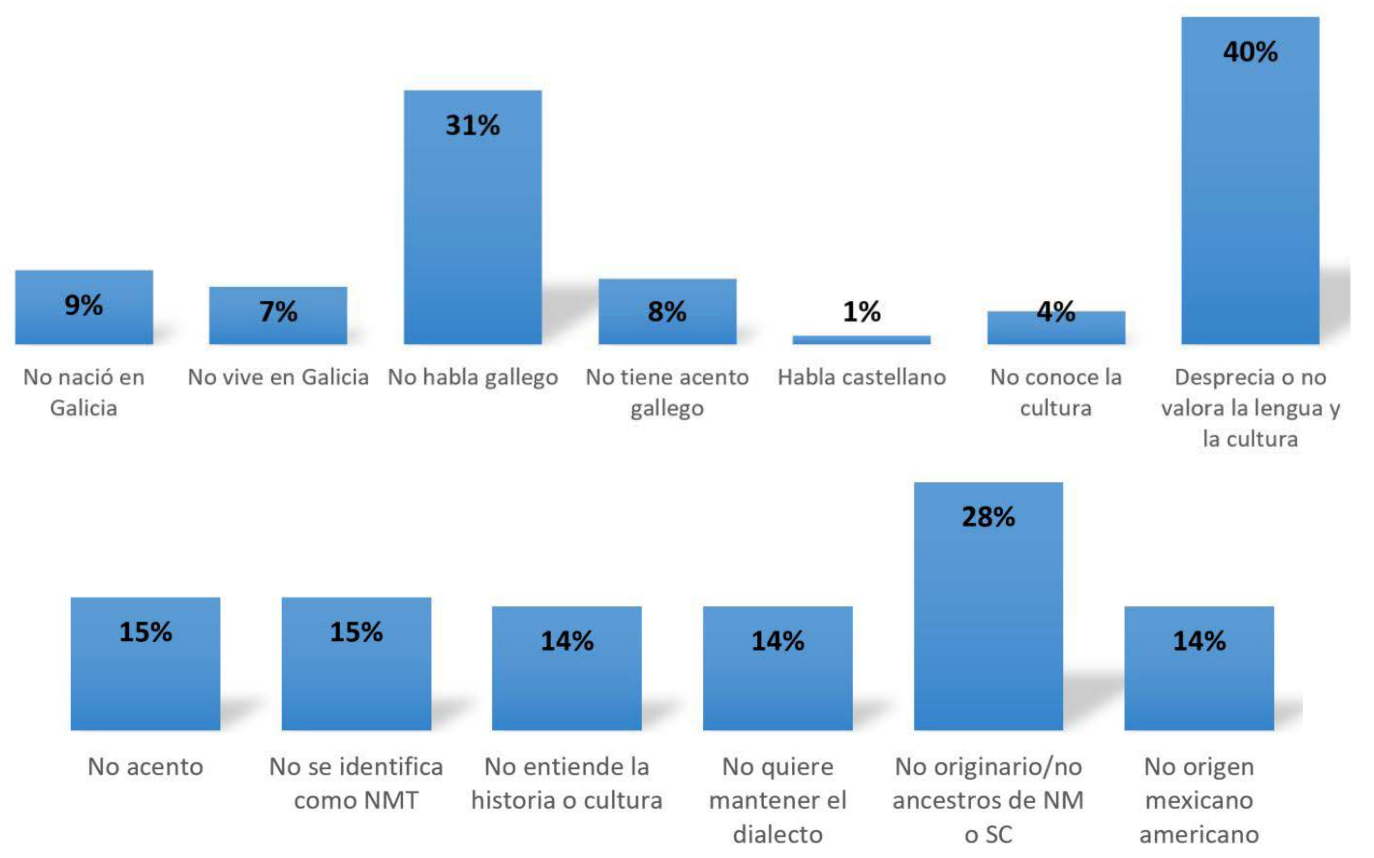

Figuras 10 (¿Quién no es gallego?) y 11 (¿Quién no es ENMT?) 


\subsection{Primera lengua}

Al preguntárseles qué lengua consideraban ser su primera lengua o lengua nativa, los participantes de Galicia (65,85\%) identificaron el gallego como su lengua 1 . Solo una minoría reporta tener como primera lengua únicamente el español o el gallego y el castellano. La mayoría $(77,78 \%)$ de los participantes del ENMT reconocen el inglés como su lengua 1 y una minoría dice tener el ENMT o el español como lengua 1. Según las respuestas de los participantes, en este proyecto de investigación el castellano en Galicia y el ENMT o español en Nuevo México y el sur de Colorado son considerados como la segunda lengua de estos grupos de hablantes.

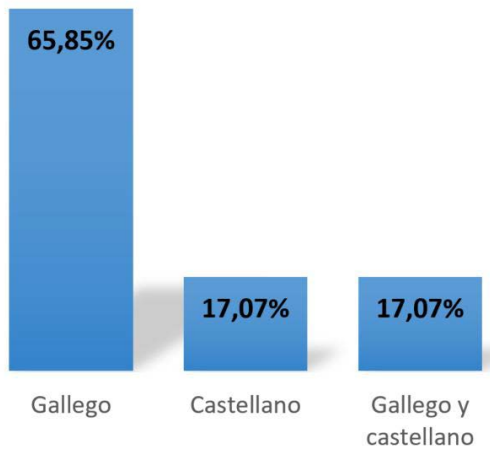

Figura 12. Primera lengua (Galicia)

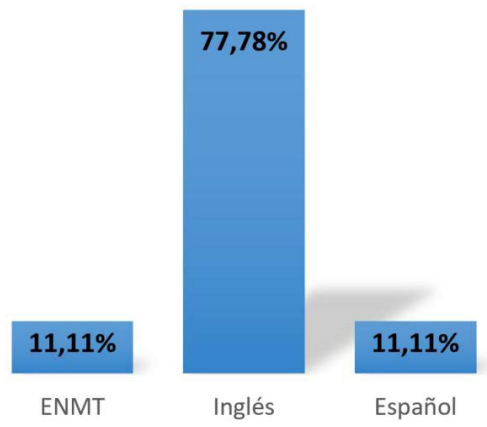

Figura 13. Primera lengua (ENMT)

\subsection{Lengua de mayor uso}

Mientras que en Galicia (fig. 14), los participantes señalan que usan el gallego y español, en la figura 15 podemos ver que el inglés es la opción escogida por todos los participantes del grupo del ENMT acompañada de un uso muy limitado del ENMT y el español.

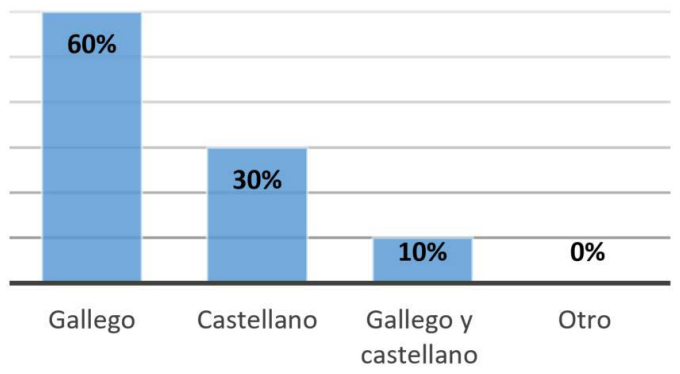

Figura 14. Lengua de mayor uso (Galicia)

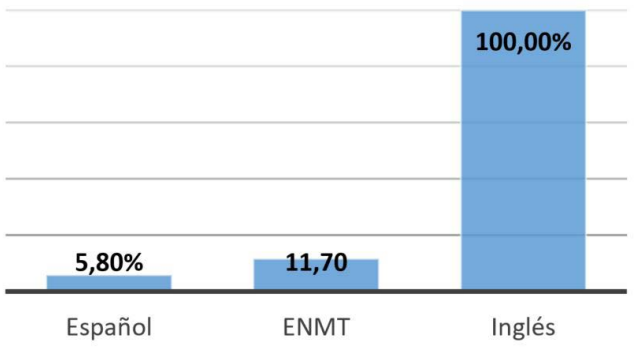

Figura 15. Lengua de mayor uso (ENMT)

\subsection{Lengua hablada en la escuela ${ }^{17}$}

En los resultados de la lengua usada en la escuela en Galicia (fig. 16) vemos una combinación de hablantes que indican usar solo gallego, hablantes que usan gallego y castellano y hablantes que usan solo castellano (la minoría). Esto es efecto de las decisiones curriculares tomadas a nivel institucional para tener clases específicas con docencia en gallego y castellano. Debido a esto, en la escuela (primaria y secundaria) en Galicia los estudiantes son expuestos a ambas lenguas. Los participantes en este estudio señalan usar más gallego que castellano. Todos los participantes que han respondido al estudio del ENMT indican unánimemente que el inglés es la lengua usada en la escuela. Solo una minoría reporta usar o haber usado el ENMT en este medio. Aunque Lipski (2008), según datos sacados de Rideling (1876) y Bohannan (1927), menciona la existencia de un número de escuelas que tenía el español como lengua de instrucción, la gran mayoría de nuestros participantes no indican haber tenido esa experiencia.

17 Debemos señalar que los resultados de este estudio pueden estar condicionados por la elección previa de los participantes, especialmente en Galicia. Los sujetos escogieron participar libremente en este estudio y esta decisión ya es de antemano representativa de su interés en el estudio de las lenguas estudiadas. 


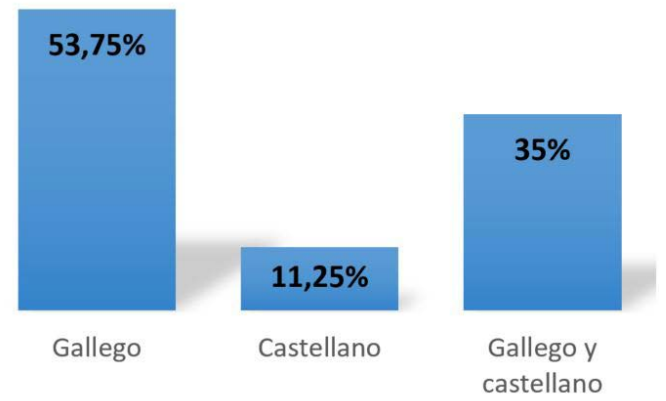

Figura 16. Lengua en la escuela (Galicia)

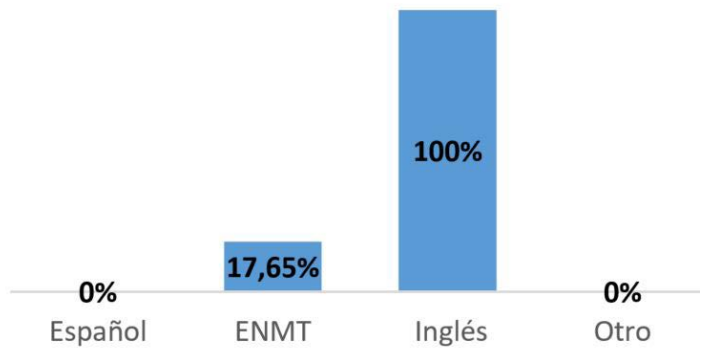

Figura 17. Lengua en la escuela (ENMT)

En Galicia, como podemos ver con mayor detalle en la figura 18, el gallego y el castellano son usados de manera activa en el medio educativo.

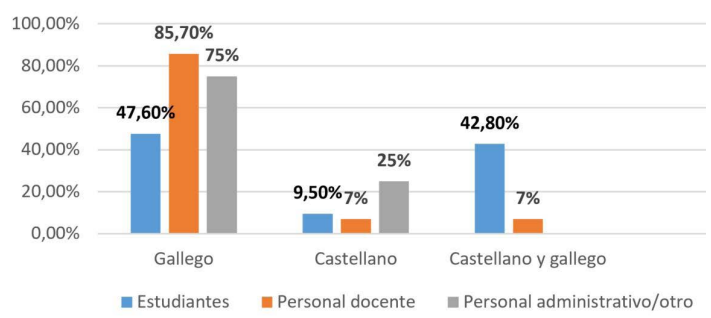

Figura 18. Lengua en la escuela (Galicia)

Según los resultados reportados en Galicia (fig. 18), el personal docente y el personal administrativo dicen usar mayormente el gallego como lengua de comunicación habitual en su lugar de trabajo. Entre los estudiantes, aunque un $47,6 \%$ dice usar gallego solamente, un $42,8 \%$ dice usar castellano y gallego al mismo tiempo.

\subsection{Lengua hablada en el trabajo ${ }^{18}$}

El gallego parece ser la lengua más usada en el trabajo escolar (fig. 19) seguida muy de cerca por el castellano en Galicia. En el área del ENMT (fig. 20) el inglés es usado por el $100 \%$ de los participantes, aunque un $11,7 \%$ reporta usar también el español y el ENMT respectivamente ${ }^{19}$.

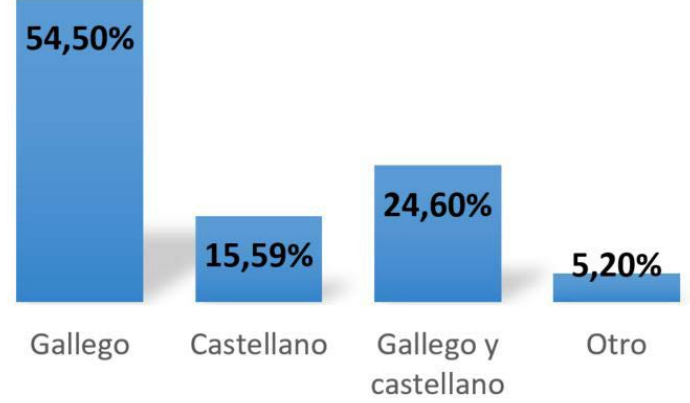

Figura 19. Lengua del trabajo (Galicia)

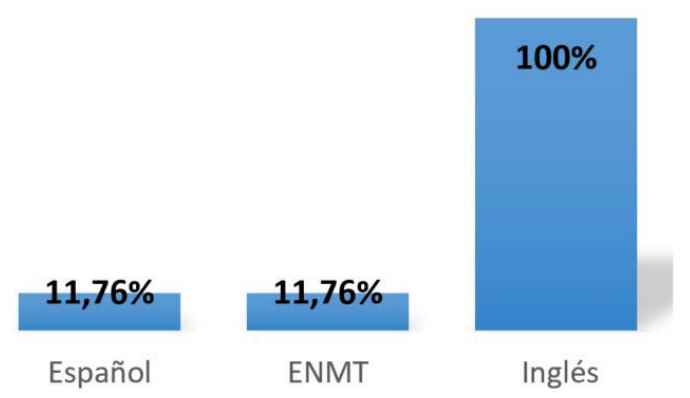

Figura 20. Lengua del trabajo (ENMT)

\subsection{Lengua de la escritura}

Los resultados de la figura 21 (Galicia) hacen referencia a la edad de los participantes. Esto es resultado del grupo encuestado: estudiantes, profesores y administradores y es, al mismo

18 Aunque el cuestionario sociolingüístico incluía preguntas diferentes buscando información sobre la lengua usada en diferentes ocasiones: en la casa, en la escuela, en el trabajo, con los amigos, con la familia, etc., en Galicia, debido a que la mayoría de las encuestas fueron completadas dentro de instituciones educativas, las categorías 'lengua del trabajo' y 'lengua de la escuela' han podido ser interpretadas como referencias al mismo contexto, ya que tanto estudiantes, como profesores y personal administrativo podían asociar la lengua usada en la escuela como la lengua usada en su lugar de trabajo.

19 En las preguntas relacionadas con la elección de lengua en diferentes contextos, se daba la opción de escoger todas las lenguas aplicables. Es decir, los hablantes podían escoger más de una lengua en cada contexto. El 100\% de los participantes en el ENMT escogieron el inglés como la lengua usada en el trabajo y también un 11,7\% reportó usar el español y el ENMT. 
tiempo, representativo de la dinámica del uso del gallego. Ninguno de los grupos reporta tener el gallego como la única lengua de escritura. El grupo de $40+$ años (67\%) dice escribir en gallego la mayor parte del tiempo, pero los más jóvenes (10-17) lo hacen un poco menos (44\%). En Nuevo México y el sur de Colorado, aunque se preguntó la edad de los participantes, los resultados no muestran diferencias entre grupos generacionales. Mientras que en Galicia (fig. 21) tanto el español como el gallego funcionan como lenguas de la escritura, en el ENMT (fig. 22) el 100\% de los participantes identifican el inglés como la lengua de la escritura, aunque un $11,76 \%$ también dice escribir en español. El 0\% reporta escribir en ENMT que, como hemos mencionado, es una variedad dialectal del español y, como tal, no ha tenido una variedad estándar y no ha sido enseñado en la escuela.

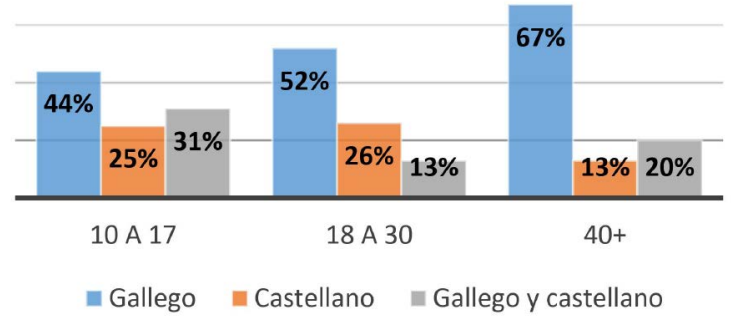

Figura 21. Lengua de la escritura (Galicia)

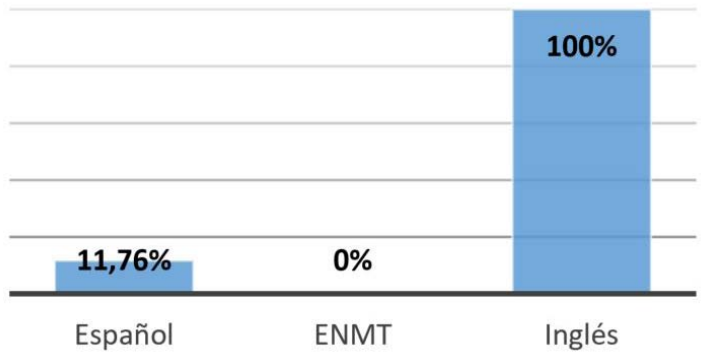

Figura 22. Lengua de la escritura $\left(\mathrm{ENMT}^{20}\right)$

\subsection{Lengua de la lectura}

Al comparar los datos de las figuras 21 y 23 no podemos dejar de observar la notable diferencia entre los índices de lectura y escritura en Galicia. Mientras que la mayoría de cada grupo de edad reporta escribir solo en gallego (fig. 21), solo una minoría de cada grupo lo hace solo en esta lengua. Podemos ofrecer varios intentos de explicación de este interesante fenómeno. Uno de ellos está relacionado con la diferencia entre los procesos de lectura y escritura. Como se explica en Castro (2015: 129) el proceso de lectura requiere no solo conocimiento del código sino una mayor comprensión de la cultura, junto con acceso a conocimiento previo y experiencias pasadas. Castro (2015) sugiere que tal vez la referencia de base para la lectura en Galicia es el castellano, no el gallego. Esto podría explicar el menor uso del gallego como lengua de lectura. Otra posibilidad sería el acceso a materiales de lectura. Aunque tenemos un buen número de materiales escritos en gallego, la mayoría de estos textos son rápidamente traducidos al castellano y suelen tener mayor acceso al público lector en castellano que en gallego (Dasilva 2009; Castro, Mainer y Page 2017).

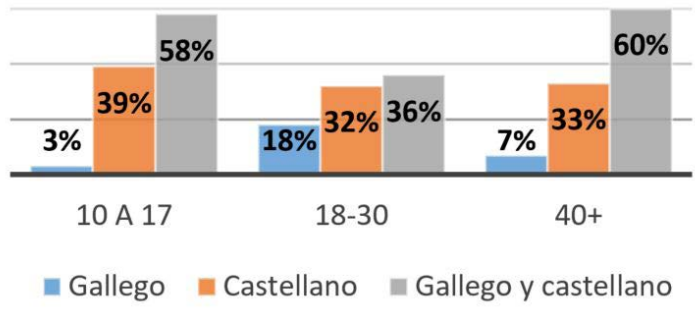

Figura 23. Lengua de la lectura (Galicia)

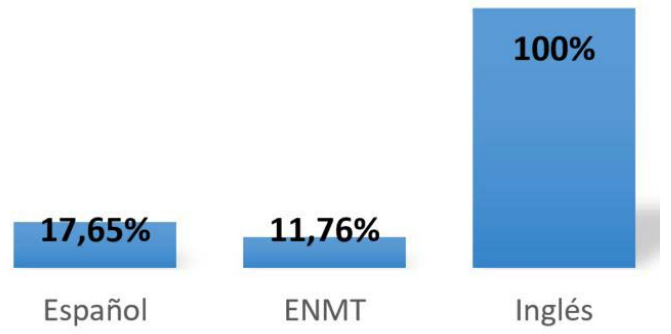

Figura 24. Lengua de la lectura (ENMT)

Las figuras 22 y 24 nos muestran que la lengua de la literacidad en el ENMT es el inglés. Es la lengua usada por el $100 \%$ de los hablantes para la lectura y la escritura. También se indica como la lengua usada en la escuela

20 Este resultado podría haber sido reportado mostrando que un $11,76 \%$ dice usar español e inglés, pero creemos que aporta mayor información el mostrar que un $100 \%$ reporta escribir en inglés y solo un $11,76 \%$ reporta escribir en español también. 
(fig. 17). Sin embargo, una minoría de los participantes reporta usar el español $(17,6 \%)$ y el ENMT $(11,7 \%)$ para leer. Ya que los participantes reportan que solo han tenido el inglés como lengua escolar, todavía nos queda la pregunta: ¿dónde han adquirido el conocimiento de lectura y escritura los grupos que reportan usar el español y el ENMT para leer y escribir? Probablemente esto haya ocurrido en casa o en clases de español como lengua extranjera o segunda lengua, pero, claramente, es algo que requiere mayor investigación. Una minoría de participantes reporta tener acceso a materiales escritos en ENMT. Este acceso viene dado a través de páginas de internet como las dedicadas a los Alabados (http://alabados.com/) y publicaciones locales que, aunque tratan de seguir las normas del español estándar, muestran claros ejemplos de léxico y estructuras nuevomexicanas.

Al preguntársele por su nivel de acuerdo con la frase "Leo más en castellano que en gallego" presentada en el cuestionario sociolingüístico, el 62,89\% (figura 25) de los participantes gallegos dice estar de acuerdo. Por su parte, el 100\% de los participantes del ENMT están de acuerdo con la frase "Leo más en inglés que en español”.

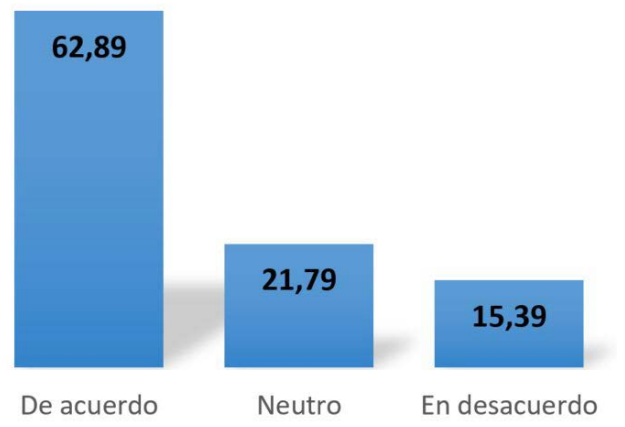

Figura 25. Lectura: más en castellano que en gallego (Galicia)

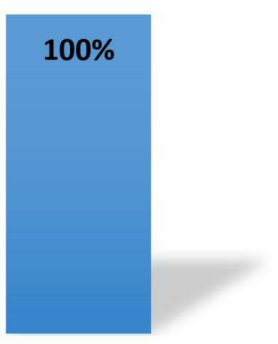

De acuerdo Neutro

En desacuerdo

Figura 26. Lectura: más en inglés que en español (ENMT)

\subsection{Lengua y cultura}

Otra de las preguntas del cuestionario sociolingüístico pedía que los participantes expresaran su nivel de concordancia con la frase "La lengua y la cultura gallegas son una y la misma cosa y no pueden ser separadas". El 79,27\% (fig. 27) de los participantes gallegos estuvieron de acuerdo con esta afirmación demostrando que todavía se mantiene una asociación entre lengua y cultura gallegas. Sin embargo, solo el 32\% (fig. 8) incluyó el hablar la lengua gallega como uno de los elementos definidores de "quién es gallego".

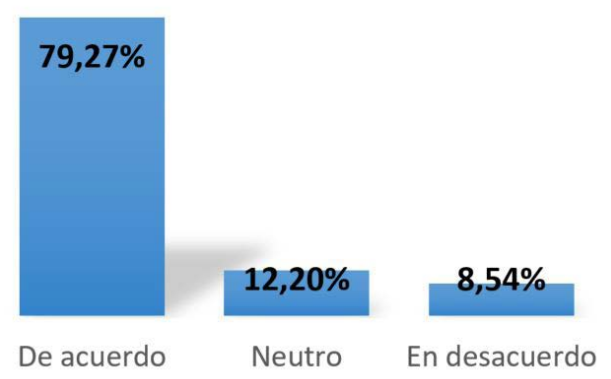

Figura 27. Lengua $=$ Cultura (Galicia)

En la encuesta del ENMT también se incluyeron frases tratando de ver en qué grado los nuevomexicanos tradicionales se identificaban con el estándar de la cultura y lengua hispanas o con la cultura y lengua nuevo mexicana tradicional.

Las figuras 28 y 29 nos muestran el grado de fragmentación de los conceptos lengua y cultura dentro del ámbito del ENMT. A primera vista podemos ver que el español estándar no es identificado con la cultura nuevomexicana (fig. 28), mientras que el ENMT sí es identificado con la cultura nuevomexicana (fig. 29). Los porcentajes de los participantes que dicen estar de acuerdo o en desacuerdo con la identificación del español estándar o el ENMT con la cultura nuevomexicana son exactamente los mismos: 47,06\% están en desacuerdo con la identificación del español estándar con la cultura nuevomexicana (fig. 28) y 47,05\% están de acuerdo con la identificación del ENMT con la cultura nuevomexicana. Esta similitud de porcentajes añade claramente credibilidad a los resultados. Sin embargo, si prestamos atención a los porcentajes de las otras opciones, podemos ver otro panorama. Esto podría ser una indicación de la desaparición de la asociación de lengua y cultura en este grupo y nos llevaría a la conclusión de que el hablar ENMT no es una parte integral de la identificación con la cultura 
nuevomexicana. Esto coincidiría, a su vez con los resultados mostrados anteriormente en la figura 11 donde pudimos ver que la presencia del acento y el mantenimiento del dialecto, aunque son considerados como elementos de identidad nuevomexicana, toman un segundo lugar ante orígenes y raíces a la hora de identificar a una persona como nuevomexicana tradicional.

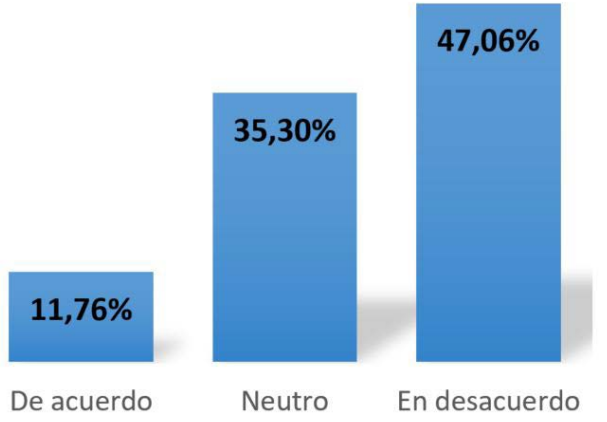

Figura 28. Lengua española $=$ Cultura nuevomexicana

\section{Conclusiones y dirección de la investigación futura}

Las situaciones lingüísticas y culturales estudiadas en este ensayo representan un contexto donde lenguas minoritarias o minorizadas en contacto con otras lenguas han estado dentro y fuera del continuum de literacidad. El gallego, después de estar fuera de este continuum durante siglos se encuentra en el medio de un proceso de estandarización que ha conducido claramente al avance del nivel de lectura y escritura en gallego. Sin embargo, el número de hablantes del gallego, especialmente en las generaciones más jóvenes, está disminuyendo. El Instituto Gallego de Estadística reporta que en 2003 el 42,98\% de la población de Galicia reportaba hablar siempre en gallego mientras que para 2013 solo el $30,84 \%$ dice hacerlo ${ }^{21}$. En 2003 el 27,10\% de la población entre 5 y 14 años reportaba hablar en gallego todo el tiempo, pero para 2013 solo el 13,20\% de este grupo dice hablar en gallego todo el tiempo ${ }^{22}$.
El ENMT, no habiendo tenido un estándar de literacidad propia (el español estándar cumplió esta función), y habiendo sobrevivido la delicada situación de su contacto con el inglés, está en proceso de desaparición al encontrarse con una nueva forma de "español estándar" por la continua llegada de inmigrantes de otras áreas del mundo hispano, especialmente de México.

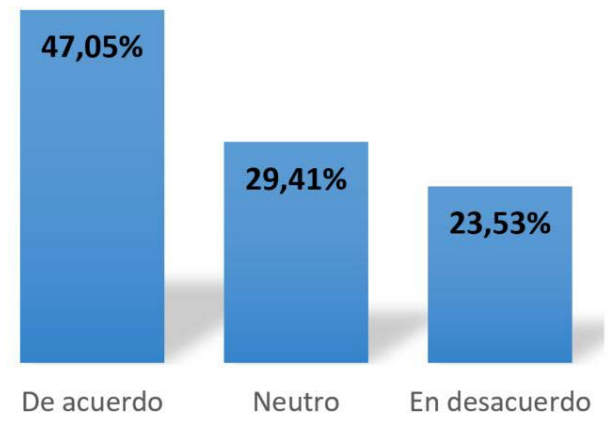

Figura 29. Lengua nuevomexicana $=$ Cultura nuevomexicana

Aunque la situación de contacto con el inglés ha afectado definitivamente el mantenimiento del ENMT, ha sido el contacto con otras variedades del español lo que ha llevado al ENMT al borde de la extinción. No obstante, los participantes en nuestro proyecto todavía son capaces de reconocer las diferencias entre el español estándar y el ENMT. Tanto los hablantes de gallego como los hablantes de ENMT se encuentran de alguna manera en la misma situación enfrentada por el grupo reconocido como "hablantes de herencia" dentro del sistema escolar. Los hablantes del ENMT empiezan a cambiar su lengua al inglés o a otra variedad del español estándar eliminando sus características originales y sustituyéndolas por una lengua: el inglés; o dos: el inglés y una variedad del español estándar. Los hablantes de gallego, por su parte, llegan a la escuela para eliminar una de sus variedades: reemplazan el gallego tradicional con el castellano mientras adquieren literacidad en gallego. Es decir, aprenden a escribir y leer en gallego, pero parecen escoger hablar en castellano ${ }^{23}$.

21 http://www.ige.eu/igebdt/esqv.jsp?ruta=verTabla.jsp?OP=1\&B=1\&M=\&COD=2951\&R=9912[12];0[0]\&C=1[0]; $2[2003] \& \mathrm{~F}=\& \mathrm{~S}=\& \mathrm{SCF}=($ consultado $10 / 11 / 2018)$.

22 http://www.ige.eu/igebdt/esqv.jsp?ruta=verTabla.jsp?OP=1\&B=1\&M=\&COD=2954\&R=4[2013];1[0];0[0]\&C=3 [0];2[0]\&F=\&S=998:12\&SCF= (consultado 10/11/2018).

23 También debemos mencionar a un nuevo, pequeño, pero en desarrollo, grupo de hablantes denominados "neofalantes" que están escogiendo usar el gallego aprendido en la escuela y difieren de los llamados hablantes tradicionales en su uso de la lengua. Uno de los elementos divergentes, es el acento gallego, aparentemente sustituido en estos hablantes por el acento castellano (O’Rourke y Ramallo, 2015). Véase también Castro 2017. 
Antes de la introducción del gallego en el sistema escolar, los estudiantes hablantes de gallego aprendían a leer y a escribir en castellano en la escuela, pero seguían hablando gallego en su casa.

La norma culta, establecida por la versión oral del español traída por los inmigrantes y asumida como estándar, ha hecho a los hablantes del ENMT esconder su variedad lingüística. De la misma manera, la norma culta de los hablantes del gallego reconocida como estándar está haciendo que los hablantes del gallego tradicional escondan su registro oral al ser percibido como subestándar. De alguna manera, la situación actual del español nuevo mexicano tradicional se asemeja a la situación actual del gallego: los abuelos hablan la lengua tradicional, pero la mayoría de sus nietos ya no lo hacen. En el caso de Nuevo México y el sur de Colorado el cambio ha sido forzado por la variedad del español "estándar" traída por los inmigrantes y en el caso gallego, por el proceso de estandarización del gallego. En ambos casos la variedad local o "tradicional" está desapareciendo por efecto de un "estándar" recién llegado (Bills 1997, 2010; Bills y Vigil 1999a, 1999b y 2008; Castro 2015, 2017).

La situación del gallego en contacto con el español comparte un gran número de características con la situación del español en contacto con el inglés en los Estados Unidos. La mayoría de los hablantes de español en los Estados Unidos son hablantes de herencia. Es decir, aunque pueden tener un nivel alto de bilingüismo, la mayoría no ha recibido instrucción formal en español. En Galicia por un largo período de tiempo, el gallego funcionó como una lengua de herencia no enseñada en las escuelas. Los niños gallegos iban a la escuela para que su lengua materna fuera reemplazada con el español castellano, la lengua de la escuela, mientras que el gallego era la lengua del hogar. Hoy, los jóvenes gallegos reciben instrucción en gallego en la escuela y reportan saber leer y escribir en gallego, pero el número de hablantes de gallego está disminuyendo, sobre todo entre los más jóvenes. En los Estados Unidos, los hablantes que tienen el español como la lengua del hogar, tienden a entrar a la escuela con el español como lengua predominante, pero suelen salir del sistema escolar con el inglés como lengua de mayor uso y en general dejan de hablar español para la tercera generación en el país.

El nivel al que el mantenimiento y cambio lingüístico es determinado por el sistema educativo y su elección de mecanismos para el desarrollo de literacidad es un fenómeno cuyo estudio necesita ser abordado y analizado cuidadosamente en vista de las selecciones lingüísticas hechas por hablantes de lenguas diferentes. Los resultados preliminares presentados en este ensayo sugieren la necesidad de prestar atención al hecho de que el proceso de literacidad no puede ocurrir en el vacío y necesita ser visto como una parte integral del desarrollo intercultural. La enseñanza de la cultura de la lengua estudiada se ha convertido en un componente intrínseco en la enseñanza de lenguas extranjeras, segundas lenguas, o en la educación bilingüe, pero las preguntas relacionadas con el concepto de cultura y qué cultura enseñar y cómo enseñarla todavía no han sido resueltas. En el contexto de la educación bilingüe y/o la enseñanza de segundas lenguas, la introducción de la cultura se puede convertir en posible adoctrinamiento: una cultura puede ser seleccionada como objeto de estudio dando lugar a que ideologías específicas puedan ser presentadas como hegemónicas. Si Galicia, Nuevo México y el sur de Colorado y otras áreas biculturales y bilingües van a tener la oportunidad de convertirse en sociedades de bilingüismo armónico, tenemos que tomar decisiones sobre no solamente cómo enseñar dos o más lenguas, sino cómo organizar la enseñanza de dos o más culturas en contacto.

\section{Referencias bibliográficas}

Acuña, Rodolfo (1988): Occupied America: A History of Chicanos. New York: Harper \& Row.

Ames, Patricia (2002): Para ser iguales, para ser distintos. Educación, escritura y poder en el Perú. Lima: Instituto de Estudios Peruanos.

Álvarez, Rosario (2017): “A lingua galega no espello. Edición e estudo de seis vilancicos cantados fóra de Galicia antes de 1650”, Madrygal. Revista de Estudios Gallegos 20 (Número especial), pp. 215-229. DOI: http://dx.doi.org/10.5209/MADR.56219.

Álvarez, Rosario y Ernesto Xosé González Seoane (2015): “O romancillo da cea do cordeiro. Texto galego do século XVII”, en F. Dubert García, G. Rei-Doval y X. Sousa (eds.), En memoria de tanto miragre. Estudos dedicados ó profesor David Mackenzie. Santiago de Compostela: Universidade de Santiago de Compostela, pp. 21-40. 
(2016): "Iluminar los Séculos Escuros: Gondomar, un orpus para el estudio del gallego en la Edad Moderna”, en J. Kabatek (ed.), Lingüística de corpus y lingüistica histórica iberorrománica. Berlin: De Gruyter, pp. 115-136.

Álvarez, Rosario y Xosé Luís Rodríguez Montederramo (2004): "Escrita epistolar en galego: a correspondencia de don Diego Sarmiento de Acuña, I Conde de Gondomar (1567-1626) (I)", Boletín da Real Academia Galega 365, pp. 253-291.

(2005): "Escrita epistolar en galego: a correspondencia de don Diego Sarmiento de Acuña, I Conde de Gondomar (1567-1626) (II)”, Boletín da Real Academia Galega 366, pp. 225-303.

Brown, Esther L. (2005): "New Mexican Spanish: Insight into the Variable Reduction of 'la ehe inihial' (/s-/)", Hispania 88/4, pp. 813-24.

Bills, Garland D. (1997): "New Mexican Spanish: Demise of the Earliest European Variety in the United States", American Speech: A Quarterly of Linguistic Usage 72/2, pp. 154-71.

Bills, Garland D. y Neddy A. Vigil (1999a): "El cambio lingüístico en el español nuevomexicano: Los factores de edad y educación”, en J. A. Samper Padilla y M. Troya (coords.), Actas del XI Congreso Internacional de la Asociación de Lingüística y Filología de la América Latina. Las Palmas de Gran Canaria: Universidad de Las Palmas de Gran Canaria / Librería Nogal, vol. 1, pp. 877-885.

(1999b): "Ashes to ashes: The historical basis for dialect variation in New Mexican Spanish", Romance Philology 53, pp. 43-67.

(2008): The Spanish Language of New Mexico and Southern Colorado: A Linguistic Atlas. Albuquerque: University of New Mexico Press.

(2010): "New Mexican Spanish: A Brief History of Time, Space, and Family Values", Southwest Journal of Linguistics 29/2, pp. 1-26.

Bohannan, Charles D. (1927): Report on survey of Chacon, New Mexico community. Made under the direction of Prof. C. D. Bohannan, Vice-Dean, School of Agriculture, NMSC, August 1927, under the auspices of the Board of National Missions of the Presbyterian Church of the USA [Unpub. ms. at the New York office of the Board].

Cassany, Daniel (2005a): "Los significados de la comprensión crítica", Lectura y Vida 26/3, pp. 32-45.

(2005b): "Navegando con timón crítico", Cuadernos de Pedagogía 352, pp. 36-39.

(2005c): "Investigaciones y propuestas sobre literacidad actual: multiliteracidad, Internet y criticidad”. Conferencia inaugural, Congreso Nacional Cátedra UNESCO para la lectura y la escritura, Sede Concepcion. Universidad de Concepción (Chile), 24-26/08/2005. En línea: http://www2.udec.cl/ catedraunesco/index.htm (21/10/2006).

Castro, Obdulia (2015): “The Orality-Literacy Continuum in Galician: Language Choice, Cultural Identity, and Language Policy at a Crossroads", en O. Castro y M. García Liñeira (eds.), Trama e urda. Contribucións multidisciplinares desde os estudos galegos. Santiago de Compostela: Consello da Cultura Galega, pp. 121-145. DOI: 10.17075/tucmeg.2015.007.

- (2017): "The Perceived Presence/Absence of Galician Accent on Galician TV Newscasts", en J. A. Losada y B. Sampedro Vizcaya (eds.), Re-routing Galician Studies. Multidisciplinary Perspectives. New York: Palgrave, pp. 205-222.

Castro, Olga; Sergi Mainer y Svetlana Page (eds.) (2017): Self-Translation and Power: Negotiating Identities in European Multilingual Contexts. New York: Palgrave (Palgrave Studies in Translating and Interpreting Springer).

Dasilva, Xosé Manuel (2009): “Autotraducirse en Galicia: ¿bilingüismo o diglosia?”, Quaderns. Revista de Traducció 16, pp. 143-156.

Domínguez-Seco, Luzia (2002): "Social Prestige and Linguistic Identity: On the Ideological Conditions behind the Standardisation of Galician", Estudios de Sociolingüística: Linguas, Sociedades e Culturas 3/2, pp. 207-228.

Esquibel, José Antonio y John B. Colligan (1999): The Spanish Recolonization of New Mexico: An Account of the Families Recruited at Mexico City in 1693. Albuquerque, NM: Hispanic Genealogical Research Center of New Mexico.

Ferguson, Charles A. (1959): "Diglossia", Word 15, pp. 325-340.

Fishman, Joshua (1967): "Bilingualism With and Without Diglossia; Diglossia With and Without Bilingualism", Journal of Social Issues 23/2, pp. 29-38.

(2007): “Maintaining Languages What Works? What Doesn't?”, en G. Cantoni-Harvey, (ed.), Stabilizing Indigenous Languages. Flagstaff, Arizona: Northern Arizona University, pp. 165-175 
González González, Manuel (1985): “La recuperación del gallego”, Revista de Filología Románica 3, pp. 101-120.

Government Report (1972): "The Excluded Student: educational Practices Affecting Mexican Americans in the Southwest. Mexican American Education Study", en Report III. Washington D.C.: Government Printing Office, pp. 76-82.

Hammer, Mitchell R. (2009): “The Intercultural Development Inventory: An Approach for assessing and building intercultural competence", en M. A. Moodian (ed.), Contemporary leadership and intercultural competence: Exploring the cross-cultural dynamics within organizations. Thousand Oaks, CA: Sage, pp. 203-217.

Hammer, Mitchell R.; Milton. J. Bennett y Richard Wiseman (2003): "Measuring intercultural sensitivity: The Intercultural Development Inventory", International Journal of Intercultural Relations 27/4, pp. 421-443.

Hammer, Mitchell R. y Milton. J. Bennett (1998-2002): The Intercultural Development Inventory. Portland, OR: The IDI Corporation.

Instituto Galego de Estatística: http://www.ige.eu/ [consultado 11/10/2018].

Likert, Rensis (1932): “A Technique for the Measurement of Attitudes”, Archives of Psychology 140, pp. $1-55$.

Lipski, John (2008): Varieties of Spanish in the United States. Georgetown, Washington D.C.: Georgetown University Press.

Lomelí, Francisco A. (1995): "Los orígenes de la cultura chicana en Nuevo México", en H. Hermans y F. Lasarte, (eds.), Literatura chicana. Foro Hispánico 9. Amsterdam: Brill / Rodopi, pp. 13-21

Lorenzo, Ramón (2004): "Emerxencia e decadencia do galego escrito (séculos XIII-XVI)", en R. Álvarez Blanco et alii (eds.), A Lingua Galega: Historia e Actualidade. Actas do I Congreso Internacional (1620 de setembro de 1996, Santiago de Compostela). Santiago de Compostela: Instituto da Lingua Galega / Consello da Cultura Galega, vol. 3, pp. 27-153.

Marí, Isidor (2005): “Leer entre dos mundos: barreras y puentes tecnológicos”, en E. Matute (ed.), Aprender a leer y a escribir en diferentes lenguas y realidades. Guadalajara (México): Universidad de Guadalajara, pp. 135-148.

Mariño Paz, Ramón (1997): “Edición do Entremés famoso sobre a pesca do río Miño (1671)”, Ensaio. Revista de teatro de Galicia e do Norte de Portugal 1, [s.p.]

- (2007): "Edición e estudo lingüístico do romance de María Francisca de Isla y Losada ao cura de Fruíme (ca. 1774-1777)”, Revista Galega de Filoloxía 8, pp. 57-98.

(2008): Historia de la lengua gallega. München: Lincom.

(ed.) (2012): Papés d'emprenta condenada (II) : lingua galega e comunicación nos inicios da Idade Contemporánea. Santiago de Compostela: Consello da Cultura Galega / Instituto da Lingua Galega.

- (2014): "A carta en galego de Magdalena García de Ogando a Martín Sarmiento. Edición interpretativa e breve comentario lingüístico", Madrygal. Revista de Estudios Gallegos 17, pp. 67-79 (http:// revistas.ucm.es/index.php/MADR/issue/view/2559).

Mariño Paz, Ramón; Xosé Ramón Barreiro Fernández y Rosa Aneiro Díaz (coord.) (2008): Papés d'emprenta condenada: a escrita galega entre 1797 e 1846. Santiago de Compostela: Consello da Cultura Galega.

Mariño Paz, Ramón y Damián Suárez Vázquez (2012): “Luís de Losada e o pranto galego pola morte de Luís I de España (1724)", Boletín da Real Academia Galega 373, pp. 325-360.

Mariño Paz, Ramón; Margarita Sánchez Yáñez y Damián Suárez Vázquez (2012): O romance da urca de Santo Antón. Poesía en galego no Ferrol do século XVIII. A Coruña: Fundación Barrié.

Monteagudo, Henrique (2007): "A emerxencia do galego-portugués na escrita instrumental. Unha panorámica histórica”, en A. I. Boullón Agrelo (ed.), Na nosa lyngoage galega. A emerxencia do galego como lingua escrita na Idade Media. Santiago de Compostela: Consello da Cultura Galega / Instituto da Lingua Galega, pp. 275-312.

(1999): Historia Social da Lingua Galega. Vigo: Galaxia

Ong, Walter J. (1982): Orality and Literacy: The Technologizing of the Word. London / New York: Methuen \& Co.

O'Rourke, Bernadette y Fernando Ramallo (2015): "Neofalantes as an active minority: understanding language practices and motivations for change amongst new speakers of Galician", International Journal of the Sociology of Language 231, pp. 147-165. 
Pérez de Villagrá, Gaspar (1992 [1610]): Historia de la Nueva Mexico, 1610. A Critical and Annotated Spanish/English Edition. Translated and edited by Miguel Encinias, Alfred Rodriguez and Joseph Sanchez. Albuquerque, NM: University of New Mexico Press.

Pew Research Center (2016): Hispanic Trends. En línea: http://www.pewhispanic.org/2016/09/08/4-ranking-the-latino-population-in-the-states/.

Ramallo, Fernando (2012): "El gallego en la familia: entre la producción y la reproducción”, Caplletra. Revista Internacional de Filología 53, pp. 167-191.

Rideling, William (1876): “A trail in the far southwest”, Harper's New Monthly Magazine 53, pp. 15-24.

Roberts, Calvin A. y Susan A. Roberts (2006 [1988]): New Mexico. New Mexico: University of New Mexico Press.

Romero, Lysette P. (2011): "Why English-Only Notice to Spanish-Only Speakers Is Not Enough: The Argument for Enhancing Procedural Due Process in New Mexico", New Mexico Law Review 41/2, pp. 603-632.

Sanz, Israel y Daniel J. Villa (2011): "The Genesis of Traditional New Mexican Spanish: The Emergence of a Unique Dialect in the Americas", Studies in Hispanic \& Lusophone Linguistics 4/2: pp. 417-442.

Sanz-Sánchez, Israel (2013): "Dialect Contact as the Cause for Dialect Change: Evidence from a Phonemic Merger in Colonial New Mexican Spanish”, Diachronica: International Journal For Historical Linguistics/Revue Internationale Pour La Linguistique Historique/ Internationale Zeitschrift Für Historische Linguistik 30/1, pp. 61-94.

Sarmiento, Fr. Martín (1995): Coloquio de vintecatro galegos rústicos. Edición de Ramón Mariño Paz. Santiago de Compostela: Consello da Cultura Galega.

(2002): Coloquio de vintecatro galegos rústicos (edición facsímil), en H. Monteagudo (ed.), Coloquio en mil duascentas coplas galegas. Santiago de Compostela: Consello da Cultura.

Skobel, Ekaterina (2010): Reversing Language Shift in Galicia: A Present-Day Perspective. Tesis de Maestría inédita. Linköping: Linköping University, Department of Culture and Communication.

Souto Cabo, José António (2008): Documentos galego-portugueses dos séculos XII e XIII (Revista Galega de Filoloxía, Monografía 5). A Coruña: Universidade da Coruña.

(2011): "A cessão do mosteiro de Armeses à condessa D a Sancha Fernandes (1222). Intersecções escriturais no primeiro documento romance da Galiza 1", Revista Galega de Filoloxía 12, pp. 217-243.

(2012): Os cavaleiros que fizeram as cantigas. Aproximição às origens socioculturais da lírica galego-portuguesa. Niteroi, Rio de Janeiro: Editora da UFF.

_ (2014): "Os primeiros escritos em galego-português: revisão e balanço", en L. Eirín y X. López Viñas (eds.), Lingua, texto, diacronía. Estudos de lingüistica histórica (Revista de Filoloxía Galega, Monografía 9). A Coruña: Universidade da Coruña, pp. 369-393.

Steele, John (2005): The Alabados of New Mexico. New Mexico: University of New Mexico Press.

Tannen, Deborah. (1982): "The Oral/Literate Continuum in Discourse", en Spoken and Written Language: Exploring Orality and Literacy. Norwood, NJ: Ablex, pp. 1-16.

(1988): "The Commingling of Orality and Literacy in Giving a Paper at a Scholarly Conference", American Speech 63/1, pp. 34-43.

Valle, José del (2000): "Monoglossic policies for a heteroglossic culture: Misinterpreted multilingualism in modern Galicia", Language and Communication 20/2, pp. 105-132.

(2015): "Ways of seeing language in nineteenth-century Galicia, Spain", en A. Havinga y N. Langer (eds.), Invisible Languages in the Nineteenth Century. Oxford: Peter Lang, pp. 281-298.

Zavala, Virginia (2002): Desencuentros con la escritura. Escuela y comunidad en los andes peruanos. Lima: Red para el desarrollo de las ciencias sociales en el Perú. 